Volume: 2, Issue: 3, September 2017, Pages: 207-210, DOI: http://dx.doi.org/10.19082/ah207

\title{
COOPERATION OF INBOUND AND OUTBOUND MEDICAL TOURISM COMPANIES: A REVIEW ARTICLE
}

\author{
Davood Safari ${ }^{1}$, Haniyeh Fattahi ${ }^{2}$
}

1: M.D, Management and Social Determinants of Health Research Center, Mashhad University of Medical Sciences, Mashhad, Iran

2: B.Sc. Student of Geography and Rural Planning, Department of Geography, Ferdowsi University of Mashhad, Mashhad, Iran

\section{TYPE OF ARTICLE: REVIEW ARTICLE}

\begin{abstract}
Medical tourism refers to travel abroad to obtain medical services. Medical tourism plays an important role in the future of medical and tourism industries throughout the world, due to the development of healthcare technologies, facilities, and some global changes. Right now, medical tourists or international patients use medical tourism agents and facilitators to find reliable providers and have trouble-free travel arrangements. Medical tourism facilitators can positively influence patients' health-seeking behaviors by advocating for patient choice, counseling, and offering support to the patient and his or her family members. One of the most outstanding facilitators of medical tourism is medical tourism companies. Depending on the type of activity, some of them refer patients to a foreign country (outbound medical tourism), some refer patients from a foreign country (inbound medical tourism), some refer patients from a city to another city in a country (intrabound medical tourism), and some are both. Medical tourism companies play a substantial role as moderator between the potential clients in a home country and medical services in destination country. The aim of this article was to review the different roles and positions of medical tourism companies. Then, the benefits of international cooperation, such as reducing marketing costs and providing appropriate medical services, are reviewed.

KEYWORDS: Medical tourism, Medical tourism facilitators, Healthcare, Tourism
\end{abstract}

\section{INTRODUCTION}

Medical tourism is more popular than ever. Right now, patients travel abroad in search of medical services that are not available or affordable in their countries $(1,2)$. This has led to improve services, increase income, and boosting tourism industries in destination countries generally (3). However, the actual number of international patients is controversial, but more than 11 million people travel around the world to receive medical services $(1,2)$. The global market share of medical tourism is US\$100 billion in 2016 with growth at a compound annual growth rate (CAGR) of $15 \%$ until 2022 (4-6). Medical tourism will play a significant role in shaping the future of medical services (7). Growth of the medical tourism industry has been facilitated by the emergence of international healthcare intermediaries or medical tourism facilitators. They inspire communication between international patients and local medical centers (8).

One of the key facilitators is medical tourism companies (MTC). Medical tourism companies work in two fields, including marketing and providing services (7-8). Some of them just play the role of providing medical services of medical tourists, while others play marketing roles (finding patients), too (6-8). The nature of their role is dependent to their position in the medical tourism industry. Some companies are in the medical tourism destination (inbound medical tourism companies [IMTC]); others are in the home country of medical tourist (outbound medical tourism companies [OMTC]); however, there are I/OMTC and intrabound MTC, but this article will not discuss them (8-18).

IMTC can easily lead international patients to appropriate medical and traveling services, due to their familiarity with the features and the culture of the destination country and easy access to service providers (10-12). However, to find health travelers, these companies have to face problems that are more complicated than providing services and

\section{Correspondence:}

Dr. Davood Safari, School of Medicine, Mashhad University of Medical Sciences, Mashhad, Iran.

Tel: +98.9126213144, Email: davoodsafarimd@gmail.com

Received: March 24, 2016, Accepted: May 22, 2017, Published: September 2017

iThenticate screening: March 30, 2016, English editing: June 29, 2017, Quality control: July 14, 2017

(C) 2017 The Authors. This is an open access article under the terms of the Creative Commons Attribution-NonCommercialNoDerivs License, which permits use and distribution in any medium, provided the original work is properly cited, the use is non-commercial and no modifications or adaptations are made. 
require high cost and a lot of time (10-13). Therefore, they have to find patients from other countries (or marketing) to be able to succeed. OMTC are somehow the opposite of IMTC because they are positioned in the home country of the international patients; in this regard, they have more information on the market, the customers, and their needs. However, to make the appropriate services, OMTC must choose providers with high quality and reasonable prices (12-15). Cooperation of IMTC and OMTC leads to reduce costs and risk and increases efficacy and availability in medical tourism. Therefore, the importance of medical tourism companies' cooperation requires more detailed study. The aim of this article is to review the different roles and positions of medical tourism companies. Then, the benefits of international cooperation, such as reducing marketing costs and providing appropriate medical services, are reviewed.

\section{LITERATURE REVIEW}

\subsection{Definitions and influences}

Medical tourism or traveling abroad for the purpose of receiving medical services is evolving as a rapidly growing market that spans the globe $(9,10)$. Today, more than 11 million people travel around the world as medical tourists (4). The travel is inbound as well as outbound, depending on the needs of the patient and the medical offerings in various countries (10). Inbound refers to patients coming into a country; outbound refers to patients traveling out of a country. It can also involve travel within the borders of the country, i.e., intrabound or domestic $(11,12)$. But, more commonly, the phrase "medical tourism" is used to describe long-distance travel to another country (13). The countries with the greatest number of inbound medical tourists in order of volume are Thailand, United States, Malaysia, Singapore, India, Mexico, Korea, Brazil, Taiwan, Turkey, and Costa Rica (14). Procedures sought by medical tourism include coronary artery bypass graft $(\mathrm{CABG})$; full face lift; gastric bypass; hip replacement; implant-supported dentures (i.e., upper and lower); in vitro fertilization cycle, excluding medication; knee replacement; porcelain bridge (i.e., four-implant); rhinoplasty; spinal fusion; and valve replacement with bypass (15).

Prominent medical tourism market drivers are

- Appropriate cost of cross-border medical treatment: Appropriate Cost

- Higher quality care and services: High Quality

Other drivers:

- Treatments and medication not approved or available in home country

- $\quad$ Large uninsured population

- Alternative/innovative therapy

- Aging population

- Long waiting time

\subsection{Medical Tourism Facilitators}

There are two ways of accessing health care for international patients: direct access and access through facilitators. They can directly visit doctors, diagnostic medical centers, pharmacies, etc. However, there are obstacles that lead them to facilitators, such as language barriers, lack of awareness about service providers that suit their illnesses and unfamiliarity with the quality and the prices offered by the service providers. If the patients have not yet chosen their destination, or they are uncertain about this choice, the facilitators can offer them good guidance. In fact, they play the role of an intermediary for introducing and providing the services that medical tourists need.

Medical tourism facilitators are facilitators that guide patients and providers. Many patients find using facilitators to be more appropriate and suitable than searching providers on their own. The facilitators know all about medical tourism, and they are able to answer all of the patients' questions and resolve any concerns they might have. They often plan and support the patient's medical travel. It is even possible that the patient receives health care with a lower cost by employing the facilitators (8). In other words, the medical travel facilitators design and implement a detailed plan for international patients by presenting comprehensive information on medical services, tourism and support services as a one-step solution (16).

Although the main goal of medical travelers is medical treatment, having a pleasant journey is considered an essential part of medical tourism. Medical tourism requires coordinated cooperation between healthcare providers 
and tourism organizations according to the patient's wishes. Medical tourism facilitators can be divided into five groups:

1. Hotels that expanded their services, to connect patients (medical tourists) with medical providers or other facilitators;

2. Travel agencies that have tour plans for health tourists to medical or wellness programs;

3. Medical Travel Planners that can be a medical tourism website, company, agency or representative who aids a patient in finding medical treatment abroad;

4. Health providers such as hospitals and doctors' groups that dedicated clinical programs for international patients (12).

Medical tourism facilitators present several medical options to patients and their families by introducing medical treatments and advanced technologies available in each particular medical destination. In the process of choosing a country or city for treatment, it is important to take advantage of a facilitator or an intermediary who is familiar with the medical services available in the destination to lead the patients to the appropriate physician and medical center.

\subsection{Medical Tourism Companies}

Medical tourism companies are among facilitators with the highest growths. These companies are sometimes introduced as agencies, presenters or planners. There are different companies working in this field in both home and destination countries (18). For example, IMTJ (International Medical Travel Journal) maintains a comprehensive directory of medical tourism facilitators and facilitators. Customers can search the IMTJ Medical Travel Directory by the country where the company is located, the country where treatment is offered by healthcare sector, and by keyword. IMTJ listed 950 medical tourism companies in its website (17).

Besides providing patients with physicians and medical centers according to their needs, medical tourism companies provide different value-added services. These services include providing flight tickets, visas, appropriate accommodations, medical consultation before the journey, and coordination between home and destination country physicians, personal nurses for the patients, medical records and follow-ups after they have returned to their countries. Therefore, by introducing and advertising the different services of healthcare and tourism industries, medical tourism companies play an important role in introducing and improving the credibility of the different services provided by a country's medical tourism industry, besides increasing foreign exchange inflow $(8,9,12)$.

\section{CONCLUSIONS}

Medical tourism companies work in two fields: marketing and providing services. However, the company may focus mostly or completely on one of them or even outsource one of them. Creating multinational companies or establishing cooperation between the medical tourism companies in the home and the destination countries leads to service providing and further strengthening of the market. Creating such companies or cooperation on the cultural, religious, and linguistic similarities can lead to maximum efficiency. How the facilitators in the home and the destination countries can cooperate with each other may be the subject of further research.

\section{ACKNOWLEDGMENTS:}

We would like to show our gratitude to the Mohammad J. Jalalian, M.D. and Vahid Reza Mohebpour, M.D. for sharing their pearls of wisdom.

\section{CONFLICT OF INTEREST:}

The authors certify that they have no involvement in any organization or company with any financial interest in the subject matter or materials discussed in this manuscript.

\section{AUTHORS' CONTRIBUTIONS:}

All authors contributed to this project and article equally. All authors read and approved the final manuscript.

\section{REFERENCES:}

1) Burkett L. Medical tourism: concerns, benefits and the American legal perspective. The Journal of Legal Medicine. 2007; 28: 223-245. DOI: 10.1080/01947640701357763. PMID: 17558794.

2) Mudur G. Hospitals in India woo foreign patients BMJ 2004; 328(7452): 1338. DOI: 10.1136/bmj.328.7452.1338. PMID: 15178611. PMCID: PMC420282. 
3) Ramirez de Arellano A. Patients without borders: the emergence of medical tourism. International Journal of Health Services: Planning, Administration, Evaluation. 2007; 37(1): 193-8. DOI: 10.2190/4857-468G2325-47UU. PMID: 17436992.

4) Medical Tourism Index. 2016. Available at: http: //www.medicaltourismindex.com/overview/. Accessed Sep 20, 2016.

5) Hansen F. A. Revolution in healthcare: medicine meets the marketplace. Public Affairs Review. 2008; 59(4): 43-45.

6) Mutchnick I, Stern D, Moyer C. Trading health services across borders: GATS, markets, and caveats. Health Affairs. 2005; 5: 42-51. DOI: 10.1377/hlthaff.w5.42. PMID: 15671085.

7) Jenner, E.A. Unsettled borders of care: medical tourism as a new dimension in America's health care crisis Care for Major Health Problems and Population Health Concerns, Impacts on Patients, Providers and Policy. Emerald Group Publishing Limited. 2008; 26: 235-249.

8) Connell J. Medical tourism: Sea, sun, sand and surgery. Tourism Management. 2006; 27(6): 1093-1100.

9) Turner L. Canadian medical tourism Facilitators that have exited the marketplace: Content analysis of websites used to market transnational medical tourism. Globalization and Health Journal. 2011; 7: 40-56. doi: 10.1186/1744-8603-7-40. PMCID: PMC3223128.

10) Plonien C, Baldwin KM. Medical Tourism: A Nurse Executive's Need to Know. AORN Journal. 2014 Oct; 4: 429-443. DOI: 10.1016/j.aorn.2014.08.007. PMID: 25260674.

11) Behrmann J, Smith E. Top 7 issues in medical tourism: challenges, knowledge gaps, and future directions for research and policy development. Global journal of health science. 2010; 2(2): 80-90. DOI: 10.5539/gjhs.v2n2p80.

12) Cormany, D. and Baloglu, S. Medical travel facilitator websites: An exploratory study of web page contents and services offered to the prospective medical tourist. Tourism management. 2011; 32(4): 709716. DOI: 10.1016/j.tourman.2010.02.008.

13) Hopkins L, Labonte R, Runnels V, Packer C. Medical tourism today: what is the state of existing knowledge? Journal of Public Health Policy. 2010; 31: 185-198. DOI: 10.1057/jphp.2010.10. PMID: 20535101.

14) Medical Tourism Statistics \& Facts. Available at: http: //www.patientsbeyondborders.com/medicaltourism-statistics-facts. Accessed Oct 12, 2016.

15) Alsharif, M.J., Labonté, R. and Lu, Z. Patients beyond borders: A study of medical tourists in four countries. Global Social Policy. 2010; 10(3): 315-335.

16) Jagyasi DP. Available at: http: //www.drprem.com/medical-tourism-facilitator/. Accessed at 8 Oct, 2016.

17) World medical tourism agents. Available at: http: //www.imtj.com/. Accessed at 9 Oct, 2016.

18) Gan LL, Frederick JR. Medical tourism facilitators: Patterns of service differentiation. Journal of Vacation Marketing. 2011; 17(3): 165-183. 